\title{
Formulation, Characterization and Evaluation of in vivo Wound Healing Potential of Lawsone Ointment
}

\author{
Farrah Abdul Khaliq*, Moosa Raza, Saeed UI Hassan, Javed Iqbal, Aysha Aslam, Muhammad Aun, \\ Muhammad Tayyab Ansari and Sahar Zahid
}

University of Lahore, Lahore, Pakistan

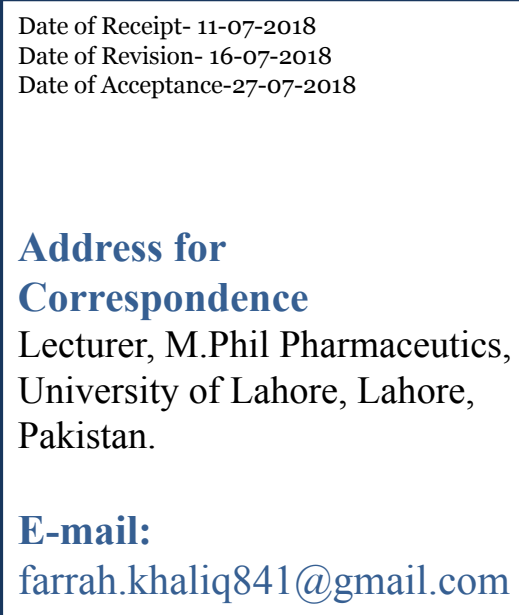

\section{Address for}

Correspondence

Lecturer, M.Phil Pharmaceutics, University of Lahore, Lahore,

Pakistan.

E-mail:

farrah.khaliq841@gmail.com

\begin{abstract}
Lawsonia inermis (henna) is well-known for its wound healing properties. Lawson has vast range of pharmacological actions from anti-inflammatory to anti-cancer. The aim of current study was to formulate an ointment of Lawson, its characterization and to evaluate its wound healing potential. Different parameters such as $\mathrm{pH}$, viscosity, specific gravity, stability parameters (texture, phase separation, odour and appearance of color) and permeability of ointment was estimated. For wound healing properties of prepared ointment, skin irritation test, spreadability of ointment and effect on histopathology of rat skin were carried out. The specific gravity of formulation OLA-1, OLA-2, and OLA3 was in acceptable range. Formulation having higher concentration of Lawson showing greater viscosity by using spindles $5 \mathrm{~s}, 6 \mathrm{~s}$ and $7 \mathrm{~s}$. The $\mathrm{pH}$ was 5.1-6.2 of calculated amount of prepared ointment. Permeability was found higher in the formulation containing greater quality of Lawson. In vivo studies showed that formulation OLA-4, OLA-5 and OLA-6 showed promising results of healing up to $57 \%$. Spreadability of all formulation ranges between $39 \mathrm{~cm}$ to $48 \mathrm{~cm}$. stability parameters and characterization showed that Lawson has enormous potential. These findings suggest that prepared ointment is excellent in wound healing management.
\end{abstract}

Keywords: Lawsonia, Drug content, Permeability, Wound healing, Spreadability

\section{INTRODUCTION}

Natural product and their derivatives contribute almost $50 \%$ of all the drugs being used in clinical world. In a number of societies traditional medicines and allopathic treatment is going side by side. In present era of medicine, plants and their extracts are getting attention by the researchers to treat ailments all over the world in a traditional way ${ }^{1}$. Lawsonia inermis normally named as Henna is known as medically effective plant. Specific biophysical limits such as temperature 19-27 degree Centigrade and rainfall around 200-4200 $\mathrm{mm}$ respectively are optimum conditions for growth of Henna Plants ${ }^{2}$. The Lawson compound has found to have antibacterial effect, antifungal effect, antiviral effect, antiparasitic effect, molluscicidal effect, tuberculostatic effect, antifertility activity, analgesic activity, anti-inflammatory activity, cytotoxic activity, antisickling activity, abortifacient activity, enzymes inhibitory activity, nematicidal activity, anticoagulant effect, protein glycation inhibitory activity and potential to cure dysentery, liver disorders, baldness, headache ${ }^{3}$.
Histopatholigical studies have revealed that a number of bioactive molecules like growth factors, cytokines, their receptors and matrix molecules play important role to regulate these steps of wound healing have been found in Lawsonia Inermis $^{4}$.

Henna leaves are used in crude form but it gives orange red color on skin and hair due to its active constituent Lawson. It is not possible to use it commonly. There was need to formulate such formulation which can be used easily to get its therapeutic effects in better way. In current study ointment formulated with minimum quantity of Lawson for its better effects to combat diseases. In the present study lawsonia ointment for topical application was formulated and characterized by drug content release, permeability, $\mathrm{pH}$, viscosity, specific gravity. Ointment was also analyzed by measuring spreadabilty index. Ex vivo characterization effects on rat skin by Histopatholigical studies and in vivo evaluation of ointment in rats by using scratch and rash method was also carried out ${ }^{5}$. 


\section{MATERIAL AND METHODS}

\section{Formulation of Ointment}

Lawsonia Inermis was ordered commercially from Sigma Aldrich in active form Lawson. The six different formulations were prepared by alternating quantity of excipients and active drug for ointment purpose. White petrolatum was used $82 \%$ and yellow bees wax was used 4\%. Quantity of Lawson was kept between 0.01 mg-0.1 mg. Optimized dosage form was finalized due to its excipients amount and also of its drug quantity. By maintaining excipients and changing its drug dose amount final dosage form was formulated and studied accordingly. Accurately weighed yellow bees wax was measured with help of weighing balance and was melted on $60^{\circ} \mathrm{C}$. Lawsonia inermis was added portion wise in melted yellow bees wax and dissolved uniformly in a beaker. Then white petrolatum was measured with help of weighing balance and was melted on $60^{\circ} \mathrm{C}$. Melted white petrolatum and all other ingredients (glycerol, paraffin oil, and cholesterol) were added in separate beaker one by one. All the components were melted and mixed geometrically. Mixture of pre-melted yellow bees wax and drug was added in it and dissolved at $60^{\circ} \mathrm{C}$. After removing heat, it was geometrically mixed continuously with spatula to get uniform dosage form.

\section{METHODOLOGY}

\section{pH}

1 gram and 2.5 gram of each formulation was added in $100 \mathrm{ml}$ of distilled water in a beaker respectively and stirred at $60^{\circ} \mathrm{C}-70^{\circ} \mathrm{C}$ for 1 hour. The solution was cooled at room temperature. $\mathrm{pH}$ of each formulation solution was measured with the help of $\mathrm{pH}$ meter ${ }^{6,7}$.

\section{Viscosity}

$10 \mathrm{~g}$ of each formulation was taken in separate beakers respectively. Beakers were placed one by one in viscometer and spindles were adjusted S5, S6, and S7 respectively at $10 \mathrm{rpm}$. Spindles were allowed to move up to 3 minutes to get fix reading. Readings were calculated in centipoise and percentages ${ }^{7}$.

\section{Specific Gravity}

A beaker was taken and after washing and drying it, weight was determined accurately using weighing balance. $50 \mathrm{ml}$ water was added in beaker and weight was determined again. Beaker was washed and dried then filled it with 50 gram of formulated ointment. The weight of beaker containing ointments was determined accordingly ${ }^{8}$.

The specific gravity of formulation was calculated using following formula:

Specific Gravity $=\frac{\text { Weight of ointment }}{\text { weight of water }}$

\section{Measurement of Drug Content}

UV absorbance for all formulations was calculated using UV spectrophotometer double beam ${ }^{7}$. The drug content of each formulation was calculated by comparing their UV absorbance value at $\mathrm{pH} 5.5$ and 7.8 with calibration curve 1 and 2. Two calibration curves were made between UV absorbance value and concentration of active drug at $\mathrm{pH}$ 5.5 and 7.8 respectively with the help of Microsoft Excel. The formula produced by each calibration curve was used for calculation of drug content according to both curves respectively.

$\mathrm{x}=\mathrm{y}-\mathrm{b} / \mathrm{x}$

$\mathrm{y}=$ Absorbance

$\mathrm{m}=$ Slope

$\mathrm{x}=$ Concentration

$\mathrm{b}=\mathrm{y}$ intercept

\section{Calculation of Permeability}

UV absorbance of samples was calculated by UV meter wavelength of $452 \mathrm{~nm}$ according to Verma et al. Permeability of all the samples was calculated by using software DDSOLVER. The permeability of each formulation was calculated by software at different $\mathrm{pH}$ according to both calibration curves. Percentage permeability of each formulation was noted on equal time intervals 1 hour, 2 hour, 3 hour, 4 hours and 5 hours respectively. Different kinetics models were applied on it to explain the drug release patterns. Zero order release kinetics, First order release kinetics, Higuchi release model, Hixon-Crowell model, Korsmeyer and Peppas release model (Table 1).

\section{Spreadability Test}

3 grams of each formulation was measured and placed between two glass slides respectively. 1000 grams of weight was applied on glass slides. Weight was placed on a petri dish to provide uniform stress to get rid of air and uniform distribution of ointment thickness. 300 grams weight was tied to a hook; other end of that hook was tied to upper slide. Lower slide was separated with force and the time used to separate both slides was recorded. The time was calculated for each formulation similarly ${ }^{9}$.

Spreadability for each formulation was calculated by using formula:

\section{$\mathrm{S}=\mathrm{M} \times \mathrm{LT}$}

Where $\mathrm{S}=$ Spreadability

$\mathrm{M}=$ Weight tied to the upper slide

$\mathrm{L}=$ Length of slides

$\mathrm{T}=$ Time recorded to separate slide 


\section{In vivo Studies of Wound Healing Activity}

8 Healthy rats were taken from Animal house. Weight of rats was determined and a deep scratch of around $1 \mathrm{~cm}$ was given near ear of each mice. Active drug, simple base and all the six formulation was applied 4 times in a day on respective mouse. The procedure was carried out for 5 days and area of scratch on each mouse was measured daily. Percentage cure for each rat was calculated ${ }^{9}$.

\section{RESULTS}

\section{pH}

$\mathrm{pH}$ of all the formulations was calculated by two methods. In first method Formulation OLA-5 Gave highest value 6.02 and The Formulation OLA-3 gave the lowest value $5.07^{9}$. Using second method Formulation OLA-5 gave the highest value 6.47 while lowest $\mathrm{pH} 5.107$ was calculated in case of Formulation OLA-2 (Figure 1).

\section{Viscosity}

At spindle S5 Formulation OLA-1 gave the highest viscosity $28719 \mathrm{CP}$ and OLA-4 gave the lowest viscosity 17.469. At spindle S6 Formulation OLA-6 gave the upper limit 19188 CP and Formulation OLA-5 gave the lowest. At spindle S7 Formulation OLA-5 gave the highest viscosity 5411.8 CP and Formulation OLA-6 gave the lowest viscosity 4622.7 (Figure 2).

\section{Specific Gravity}

Specific gravity of formulations was found $0.87,0.91$, $0.81,0.85,0.86$ and 0.91 respectively.

Highest specific gravity was 0.91 and lowest specific gravity was 0.085 as shown in Table 2 .

The specific gravity variation of different ointments in demonstrated in (Figure 3).

\section{Drug Content}

Using Calibration Curve 1 (Figure 4) Drug Content ranges from 0.764 (Formulation OLA-1) 1.716 (Formulation OLA-6) at $\mathrm{pH}$ 5.5. Similarly Drug content at $\mathrm{pH} 7.8$ produced lower limit 0.029 (Formulation OLA-1) and higher limit of 0.715 (Formulation OLA-6). Using Calibration curve 2 (Figure 5) Drug Content ranges from 0.764 (Formulation OLA-1) 1.716 (Formulation OLA6) at $\mathrm{pH}$ 5.5. Similarly Drug content at $\mathrm{pH} 7.8$ produced lower limit 0.029 (Formulation OLA-1) and higher limit of 0.715 (Formulation OLA-6) (Table 3).

\section{Calculation of Permeability}

In Buffer 7.8 the permeability ranges from $1.25435 \mathrm{~d}$ of OLA-1 to $12.36934 \mathrm{~d}$ of OLA-6 (Figure 6). In Buffer 5.5 the permeability ranges from $0.21957 \mathrm{~d}$ of OLA-1 to $8.19821 \mathrm{~d}$ of OLA-6 (Figure 7). Percentage drug release in buffer 5.5 and 7.8 using in vitro technique by application of Zero order release kinetics, First order release kinetics, Higuchi release model, Hixon-Crowell model, Korsmeyer and Peppas release model are enlisted in Tables 4 and 5 respectively.

\section{In vivo Study of Wound Healing Activity}

The length of scar decreased from $1 \mathrm{~cm}$ on day 1 to 0.39 at day 6 in rat treated with active drug. The percentage cure in case of active drug was $71 \%$. In case of rat treated with base only the healing rate was $2 \%$ with only length reduced by $0.02 \mathrm{~cm}$ on day 6 . The length of scar reduced from $1 \mathrm{~cm}$ on day 1 to 0.43 at day 6 in mice treated with Formulation OLA- 6 with percentage cure of $57 \%$. The percentage cure in case of Formulation OLA- 5 was $46 \%$ as the length of scar reduced from $1 \mathrm{~cm}$ on day 1 to 0.54 at day 6 . Similarly in case of Formulation OLA-4, OLA-3, OLA-2 and OLA1 the length of scar decreased from $1 \mathrm{~cm}$ on day 1 to 0.61 , $0.89,0.91$ and 0.94 at day 6 respectively. The healing potential was $39 \%, 11 \%, 9 \%$ and $6 \%$ accordingly (Figures 8 and 9).

\section{DISCUSSION}

Plants friendship with humans for the wellbeing of human is quite remarkable. Natural substances can support health and lighten illness is basically prime idea for the development of herbal medicines. Herbal remedies have become a trend now days as people are switching to herbal way of treatment. Western drugs also their origin in plant extract. According to Lochhead et al. specific gravity of stable and quick breaking topical skin composition ranges between 0.75-0.91, Formulation OLA-1, OLA-2 and OLA3 were in this ideal range 9 . Drug delivery of semisolid dosages depends on the rheological properties. Viscosity may directly control the diffusion rate of drug. Formulation OLA 6 was excellent for skin treatment as it $\mathrm{pH}$ is close to Skin $\mathrm{pH}$. Aukunuru et al. showed that enhanced release of drugs has also been obtained by super saturation of the ointment base ${ }^{10}$. In this study, we effectively used a cosolvency technique to obtain the same results. Our results are in exact concordance with these findings. High skin permeability in case of ointment is indicator of higher drug release, provided that that drug partitioning into the skin is not an issue. Super saturation of the ointment base and co-solvency technique can be used to get increased release of drugs and optimal results. The FDMRA assay has been proven successful to optimize the formulation of ointment statically.

Nayak et al. used Ethanolic extract of Lawsonia inermis to study healing of wounds on rat's incision, excision and dead space wound models. It was found that extracted henna leaves having $71 \%$ efficacy exactly as in case of pure drug our study indicated that healing rate is $71 \%$ in case of pure drug ${ }^{11}$. According to Fahad, Natural henna is usually hypoallergenic and allergic reactions occurred in mixed types including black henna ${ }^{12}$. The patch test is 
the gold standard method for diagnosis of allergic contact dermatitis from henna, while the prevalence of the positive patch test in pure henna is 3 percent only, the directive of the European Community Cosmetics Directive, which allows the maximum concentration to be $6 \%$. Nayeem and Karvekar, showed that the Spreadability of all gels was found to be between the ranges of $5.2 \mathrm{~cm}$ to $6.6 \mathrm{~cm}$. In contrast our study showed that Spreadability of all formulation ranges between $39 \mathrm{~cm}$ to $48 \mathrm{~cm}$.

\section{CONCLUSION}

This study was first time conducted in Pakistan for topical application of Lawsonia and showed promising results. The ointment formulation, characterization, spreadability, and in vivo studies indicate that it can be an excellent breakthrough in field of pharmaceutics. Additional biochemistry studies are required to sequester the active compound in authority for these pharmacological actions. Boosted wound shrinkage, improved skin breaking strength and antimicrobial potential suggest that future belongs to use of $\mathrm{L}$. inermis in the managing of wound healing.

\section{REFERENCES}

1. Kamal M, Jawaid T. Pharmacological activities of Lawsonia inermis Linn: A review. International Journal of Biomedical Research. 2010;1(2):37-43.

2. Orwa C, Mutua A, Kindt R, et al. Agroforestree database: A tree species reference and selection guide version 4.0. World Agroforestry Centre ICRAF, Nairobi, KE. 2009.

3. Shivananda BN, Shivananda NB. Maniple Manuel of Clinical Biochemistry. Jaypee Brothers, Medical Publishers Pvt. Limited. 2007.

4. Mehta D, Sharma AK. Trichosanthes dioica (Roxb.):
A review on pharmacological update. Inventi. 2012;12:172.

5. Najmuddin M, Shelar SA, Ali AS, et al. Formulation and in vitro evaluation of floating microspheres of ketoprofen prepared by emulsion solvent diffusion method. Int J Pharm Pharm Sci. 2010;2:13-17.

6. Verma A, Singh S, Kaur R, et al. Formulation, optimization and evaluation of Clobetasol Propionate gel. International Journal of Pharmacy and Pharmaceutical Sciences. 2013;5(4):666-674.

7. Buhse L, Kolinski R, Westenberger B, et al. Topical drug classification. International Journal of Pharmaceutics. 2005;295(1):101-112.

8. Nayeem N, Karvekar MD. Anti-microbial and antioxidant properties of the isolated compounds from the methanolic extract from the leaves of Tectona grandis. Journal of Basic and Clinical Pharmacy. 2011;2(4):163.

9. Lochhead RY, Castaneda JY, Hemker WJ. Inventors: The BF Goodrich Company, assignee. Stable and quick-breaking topical skin compositions. United States patent US 5,004,598. 1991.

10. Aukunuru JV, Ayalasomayajula SP, Kompella UB. Nanoparticle formulation enhances the delivery and activity of a vascular endothelial growth factor antisense oligonucleotide in human retinal pigment epithelial cells. Journal of Pharmacy and Pharmacology. 2003;55(9):1199-1206.

11. Nayak BS, Isitor G, Davis EM, et al. The evidence based wound healing activity of Lawsonia inermis Linn. Phytotherapy Research. 2007;21(9):827-831.

12. Fahad S, Hussain S, Saud S, et al. Exogenously applied plant growth regulators affect heat-stressed rice pollens. Journal of Agronomy and Crop Science. 2016;202(2):139-150. 
Table 1. Kinetics Models

\begin{tabular}{|c|c|c|}
\hline Model & Purpose & Formula \\
\hline Zero order & $\%$ age drug release verses time is linear & $\mathrm{C}=\mathrm{kot}$ \\
\hline First order & Log $\%$ age drug release verses time is linear & og $\mathrm{C}=\log \mathrm{Co}-\mathrm{kt} / 2.303$ \\
\hline Higuchi model & $\%$ age drug release versus square root of time is linear & $\mathrm{Q}=\mathrm{k} 1 \mathrm{t} 1 / 2$ \\
\hline $\begin{array}{l}\text { Hixon - Crowell } \\
\text { model }\end{array}$ & $\begin{array}{c}\text { Original drug mass, weight and mass, weight at time versus time is } \\
\text { linear }\end{array}$ & $\mathrm{Qo}^{1 / 3}-\mathrm{Qt}^{1 / 3=} \mathrm{kHCt}$ \\
\hline \multicolumn{2}{|c|}{ Korsmeyer and Peppas model } & $\mathrm{Mt} / \mathrm{M} \infty=\mathrm{kkpt}^{\mathrm{n}}$ \\
\hline
\end{tabular}

Table 2. Percentage drug release in Buffer 7.8 by application of Zero order release kinetics, First order release kinetics, Higuchi release model, Hixon-Crowell model, Korsmeyer and Peppas release model

\begin{tabular}{|c|c|c|c|c|c|}
\hline \multirow{2}{*}{ Zero order $\left(\mathbf{R}^{2}\right)$} & \multirow{2}{*}{ First order $\left(\mathbf{R}^{2}\right)$} & \multirow{2}{*}{ Higuchi model $\left(\mathbf{R}^{2}\right)$} & \multirow{2}{*}{ Hixon Crowell $\left(\mathbf{R}^{2}\right)$} & \multicolumn{2}{|c|}{ Korsmeyer and Peppas } \\
\hline & & & & $\left(\mathbf{R}^{2}\right)$ & $\mathbf{N}$ \\
\hline 0.9876 & 0.9881 & 0.8642 & 0.9825 & 0.9901 & 0.88 \\
\hline 0.9864 & 0.987 & 0.8662 & 0.9807 & 0.9893 & 0.873 \\
\hline 0.9978 & 0.9975 & 0.8191 & 0.9967 & 0.9971 & 1.021 \\
\hline 0.8765 & 0.8721 & 0.9786 & 0.7472 & 0.9841 & 0.565 \\
\hline 0.8891 & 0.8933 & 0.9241 & 0.8009 & 0.9325 & 0.615 \\
\hline 0.9467 & 0.951 & 0.9094 & 0.9168 & 0.9642 & 0.723 \\
\hline
\end{tabular}

Table 3. Drug Content of different formulations in buffers of different $\mathrm{pH} 5.5$ and 7.8 using Curve 1

\begin{tabular}{|c|c|c|}
\hline Formulations & Drug content in buffer pH $5.5(\mathrm{~g})$ & Drug content in buffer pH $7.8(\mathrm{~g})$ \\
\hline OLA-1 & $0.764 \pm 0.008$ & $0.029 \pm 0.006$ \\
\hline OLA-2 & $0.84 \pm 0.025$ & $0.107 \pm 0.02$ \\
\hline OLA-3 & $0.882 \pm 0.015$ & $0.519 \pm 0.04$ \\
\hline OLA-4 & $0.921 \pm 0.012$ & $0.607 \pm 0.026$ \\
\hline OLA-5 & $1.068 \pm 0.029$ & $0.627 \pm 0.021$ \\
\hline OLA-6 & $1.176 \pm 0.012$ & $0.715 \pm 0.04$ \\
\hline
\end{tabular}

Table 4. Drug Content of different formulations in buffers of different $\mathrm{pH} 5.5$ and 7.8 using Curve 2

\begin{tabular}{|c|c|c|}
\hline Formulations & Drug content in buffer pH 5.5 (g) & Drug content in buffer pH 7.8 (g) \\
\hline OLA-1 & 0.331 & 0.104 \\
\hline OLA-2 & 0.377 & 0.058 \\
\hline OLA-3 & 0.401 & 0.186 \\
\hline OLA-4 & 0.424 & 0.238 \\
\hline OLA-5 & 0.511 & 0.208 \\
\hline OLA-6 & 0.575 & 0.302 \\
\hline
\end{tabular}

Table 5. Percentage drug release in Buffer 5.5 by application of Zero order release kinetics, First order release kinetics, Higuchi release model, Hixon-Crowell model, Korsmeyer and Peppas release model

\begin{tabular}{|c|c|c|c|c|c|}
\hline Zero order (R2) & First order (R2) & Higuchi model $\left.\mathbf{( R}^{2}\right)$ & Hixon Crowell $\left(\mathbf{R}^{2}\right)$ & \multicolumn{2}{|c|}{ Korsmeyer and Peppas } \\
\hline & & & & $\mathbf{N}$ \\
\hline
\end{tabular}




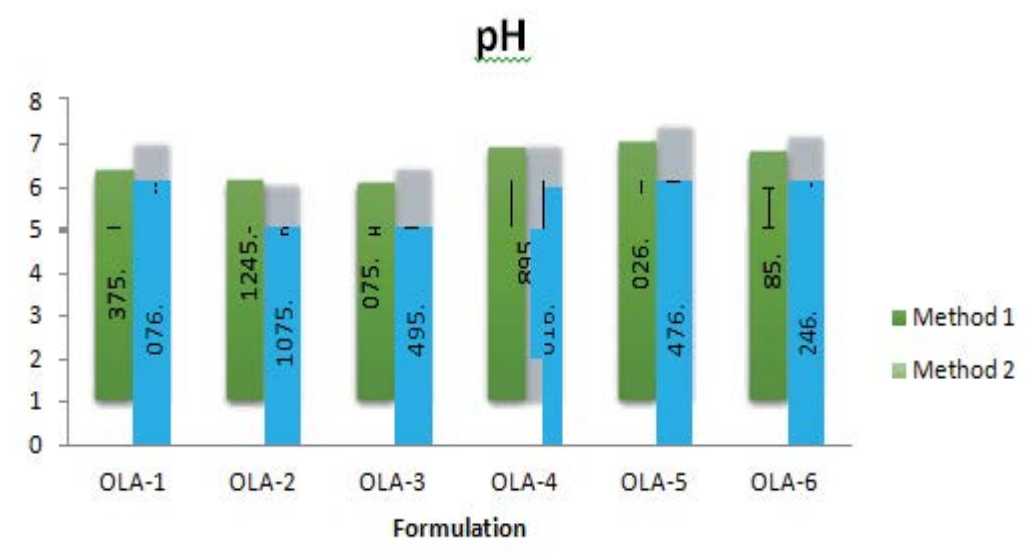

Figure 1. Calculation of $\mathrm{pH}$ of formulations by both methods

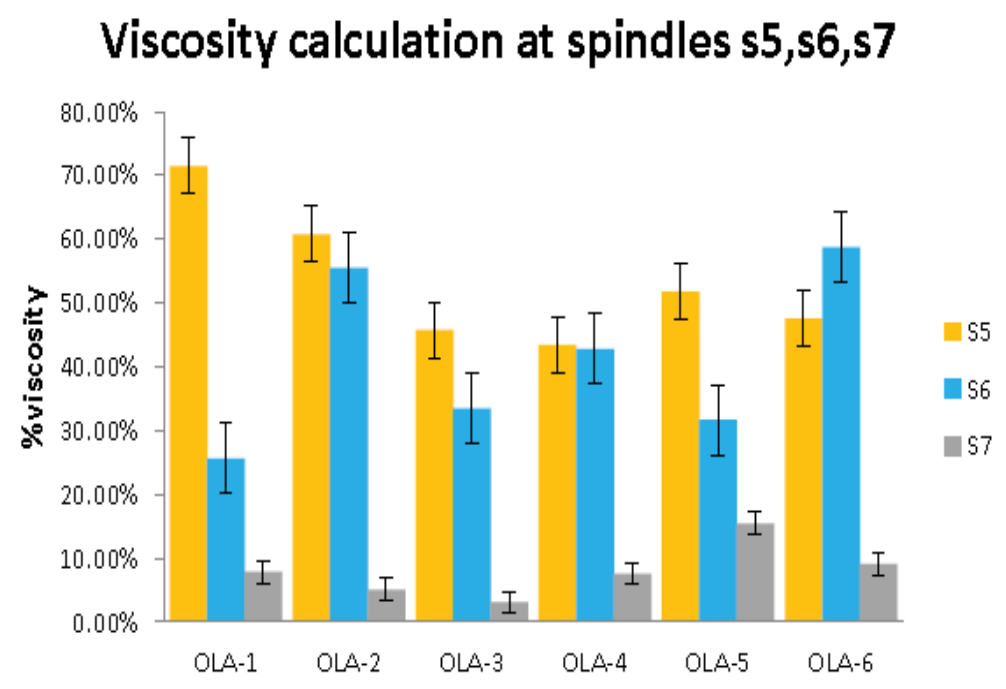

Figure 2. Viscosity trend of formulations at $5 \mathrm{~s}, 6 \mathrm{~s}$ and $7 \mathrm{~s}$

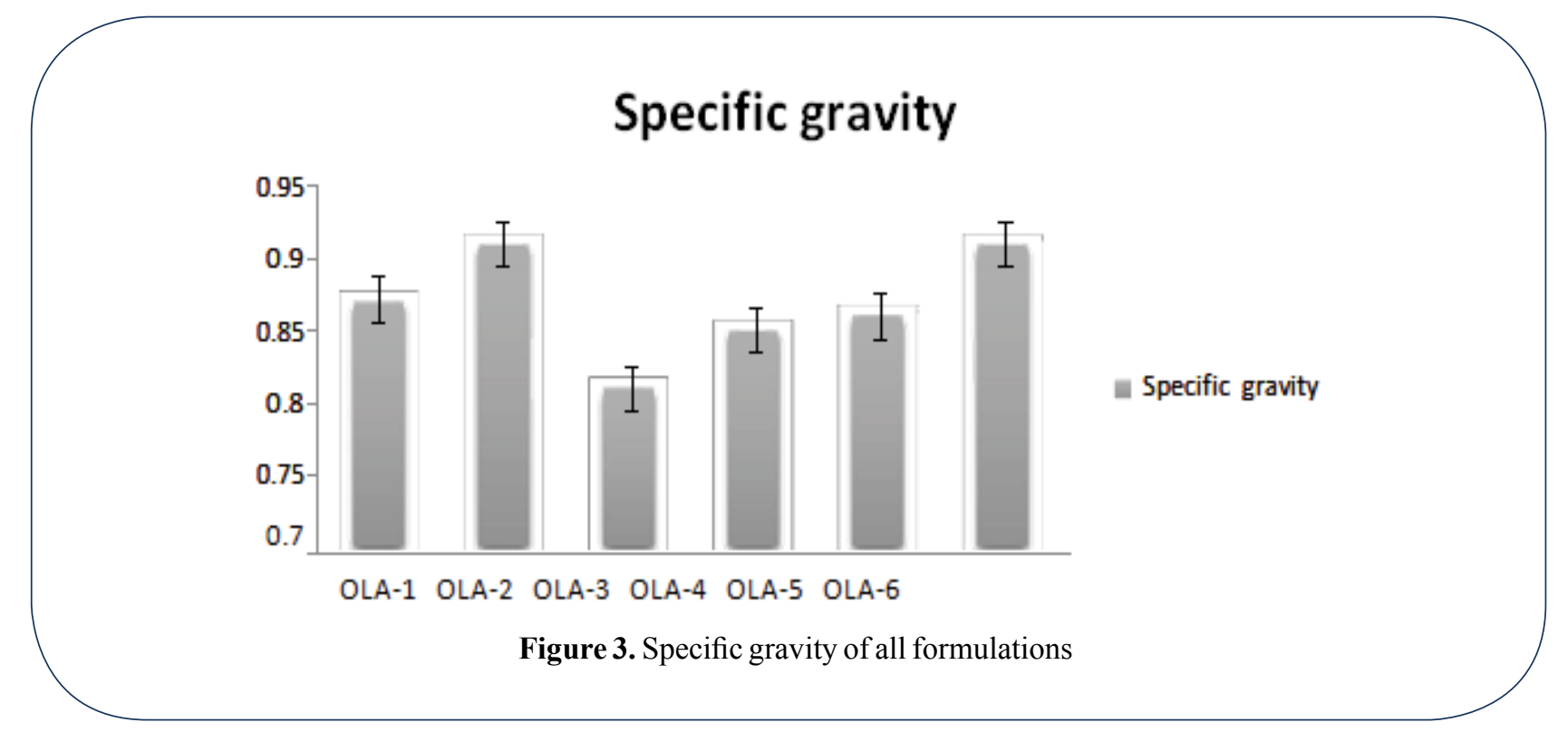



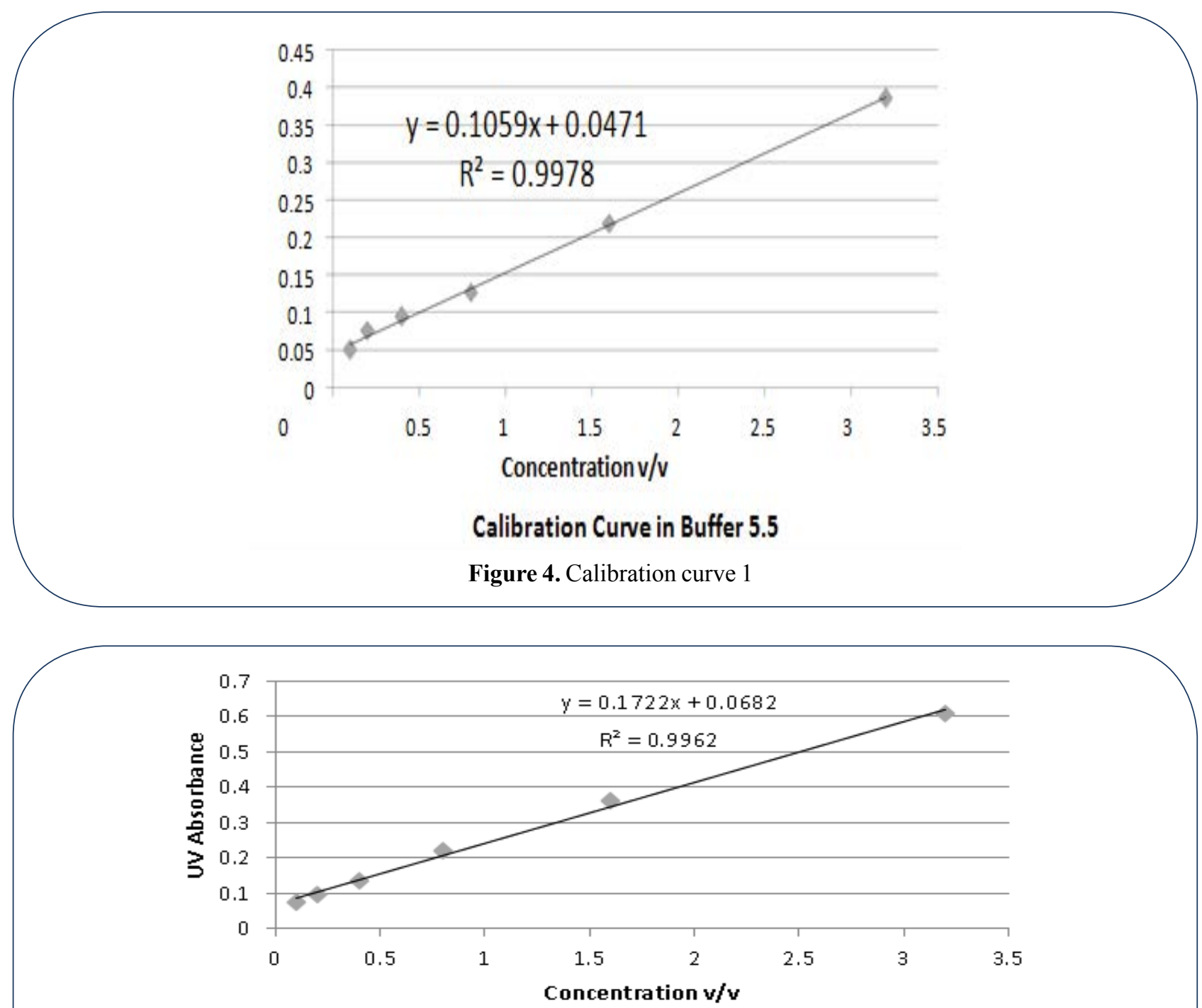

Calibration Curve in Buffer 7.8

Figure 5. Calibration curve 2

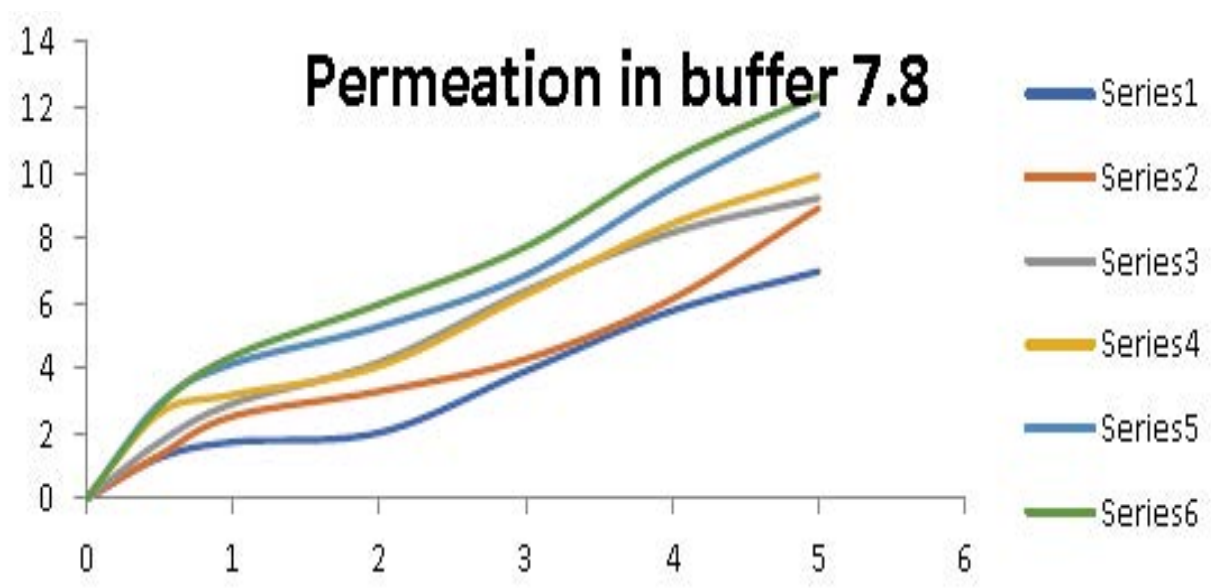

Figure 6. Permeability calculations of samples taken at different intervals from all formulations in buffer 7.8 


\section{Permeation in buffer $\mathbf{5 . 5}$}

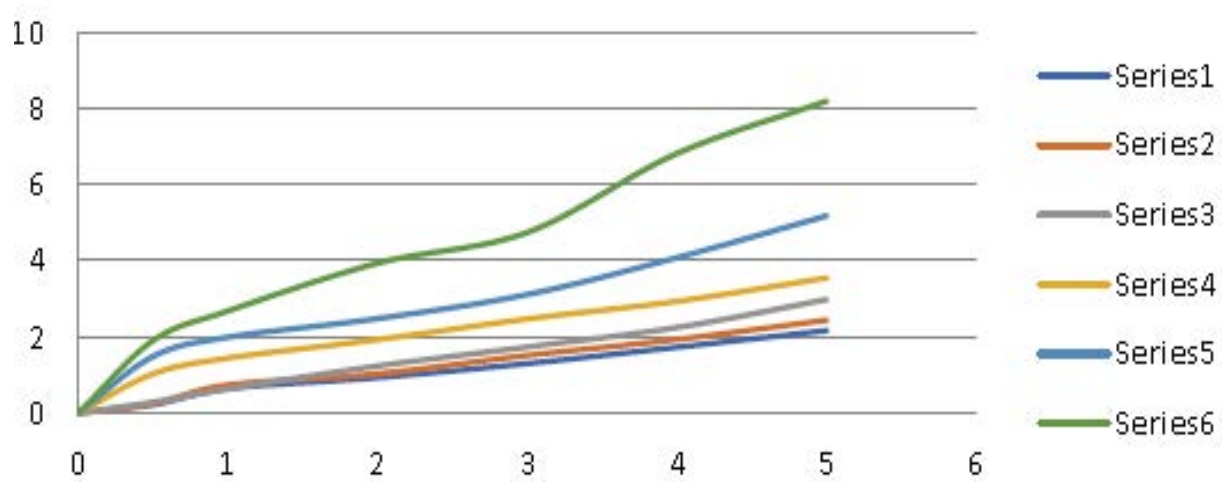

Figure 7. Permeability calculations of samples taken at different intervals from all formulations in buffer 5.5

\section{Spreadibilty}

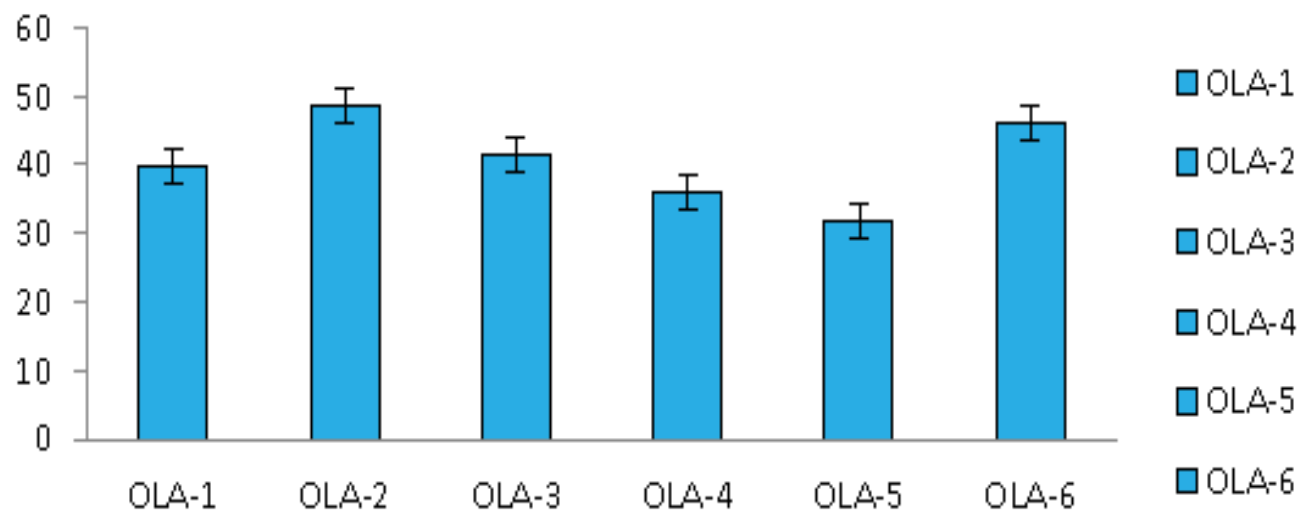

Figure 8. The Spreadabilty variation behavior of all formulations

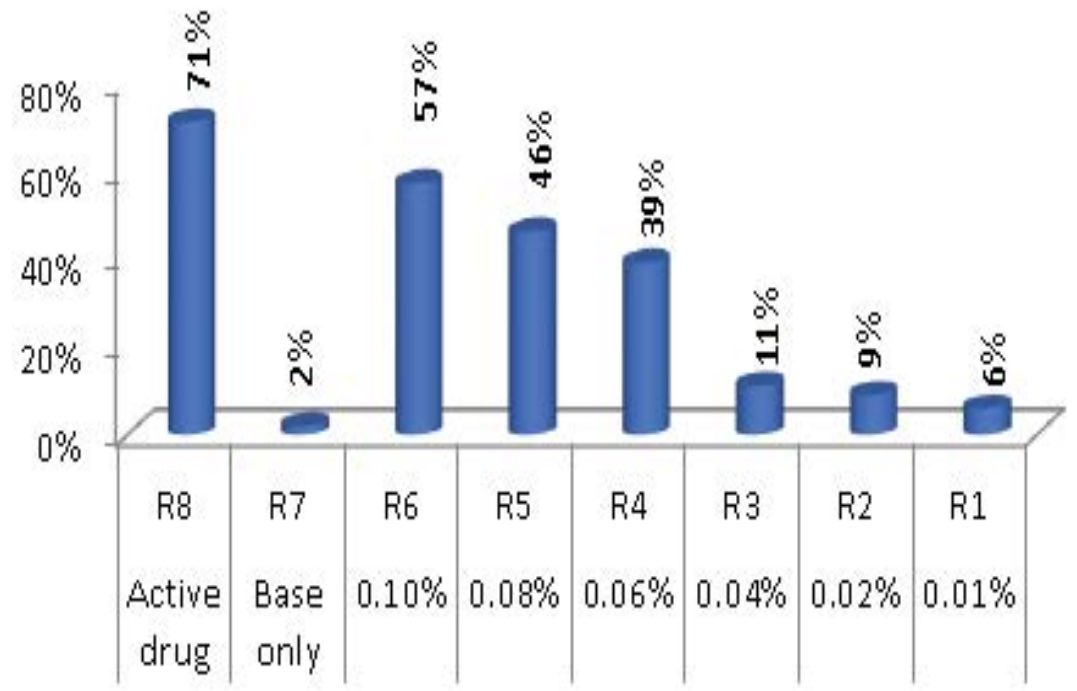

\%age cure

Figure 9. Comparison of healing potential of all the formulations, active drug and pure base 